\title{
(In)Conveniently Disposable: Waste Concern doesn't Affect Plastic Consumption
}

\author{
Angela T. Ragusa and Andrea Crampton
}

\begin{abstract}
Mixed-methods analysis of $>400$ online social surveys conducted at an Australian organisation is presented to identify individuals most likely to consider the environmental impact of packaging when making purchase decisions, including bottled water, and/or take their own shopping bags/coffee cups to minimise plastic consumption. Findings are compared for two social groups, the minority $(33 \%)$ who articulated 'waste' as a personal environmental concern, and the majority. With high disposable coffee cup consumption existing alongside 'most' product-choices based on their pro-environmental packaging, findings further green 'attitude/behaviour' gap explorations. Given legislated plastic reduction initiatives yielded greatest individual behavioural change (bringing/reusing grocery bags) regardless of respondents' waste-production concern, continued promotion of consumer preference-based, non-punitive incentives promoted in research literature may come at high ecological cost.
\end{abstract}

Index Terms-Environmental sociology, bottled water, plastic packaging, consumer decision making, social attitudes, environment and behavior.

\section{INTRODUCTION}

Plastic packaging remains an environmental blight, for reasons extensively documented about its negative consequences to human [1], [2], animal [3], and environmental health [4]. Whilst modest progress is being made to reduce human production and consumption of disposable, single-use plastics, in Australia, as globally, plastic 'packaging' remains the most consumed plastic source and the greatest contributor to municipal landfill [5], substantially contributing to environmental degradation [6]. Single use plastics from packaging make up a large proportion of the 12 million tonnes of plastic that pollute the world's oceans each year [3] choking marine life from plankton to blue whales [7]. Terrestrially, plastics contribute to large rubbish mounds in India, China, and other developing countries, contaminate available land space across many island nations, and leach toxins into the soil and groundwater to the global detriment of humans and animals alike [8], [9].

Disposable coffee cups, shopping bags, and water bottles are three single-use plastic products with a sizable, negative environmental impact in the research location. Disposable coffee cups are an example of contemporary 'packaging' that Australian society broadly, and the organisation from which the research sample was drawn specifically, has been trying

Manuscript received January 3, 2021; revised May 28, 2021

The authors are with the Charles Sturt University, Albury, Australia (e-mail: aragusa@csu.edu.au, acrampton@csu.edu.au). to address using 'soft' behavioural change solutions. The creation of aesthetically-designed 'KeepCups', as one of many 'bring-your-own' alternatives to single-use cups, and encouragement of their usage through ongoing price discounts, signage, and other 'opt-in' measures, are organisational and national 'soft' pro-environmental change incentives. With plastic taking up to 400 years to degrade, buying a disposable plastic-derived coffee cup, where only 1:400 are recycled in the UK despite the existence of several recycling options not present in Australia [3], is an unnecessary, anti-environmental action frequently practiced by a diverse range of individuals with varying levels of environmental concern and knowledge. Nationally and globally, service economies supporting cultural habits that rely on 'consumer choice', when multiplied by population size, have disastrous, long-term environmental consequences.

In contrast, single-use plastic shopping bags have pursued a different trajectory in Australia, following trends in many countries and cities around the globe [10]. Once provided with any purchase, today, Australian legislation requires supermarkets to only supply 'reusable' bags that come with a nominal cost [11]. Non-grocery retailers also are legislated to avoid 'single-use' plastic bags, yet may, at their discretion, not pass on their cost to consumers [11]. This 'waste' item thus offers a point for comparison given there exists less consumer incentive to 'bring-your-own-bag' anywhere other than to supermarkets. Further, despite Australian supermarket giants (i.e. Coles and Woolworths) responding to consumer lament over 'excessive packaging', and mass media coverage of the topic [12], single-use plastic packaging for most consumer objects fills waste management centres, with only $15-21 \%$ recycled [5]. Since neither the production, nor repackaging of plastics has attenuated the environmental problems plastic pose that prompted governmental plastic bag bans and container recycling scheme introductions in Australia [4], and consistent with the international literature shortly discussed, 'general' awareness of environmental issues appears an insufficient mechanism for changing consumer or supplier behaviour.

Bottled water, compared with disposable coffee cups and shopping bags, differs again as a disposable plastic product. In Australia, buying bottled water is a well-known practice contributing to plastic production and environmental pollution [13]. Research identifies a minority (21\%) is purchased for its 'convenience' and, compared with earlier decades, the product has become disassociated with social status and/or lifestyle [14], key elements commonly discussed with social capital theory around conspicuous consumption behaviours. Literature shows reasons why 
consumers buy bottled water remain embroiled with health risk perceptions, a cultural change accompanying product marketing shifts away from promoting its convenience towards health consciousness campaigns [15]. Concurrently, research shows Australian media reporting sensationalising water contamination events [14]. Together, these social environmental factors encourage bottled water consumption. However, if drinking water bottled in plastic is marketed and consumed for 'health' reasons, this is problematic because, as scientists note, the general public has insufficient health literacy to make such determinations [16]. Moreover, the plastic contained in drinking water bottles is toxic to the environment and humans [17]-[19].

Despite governments and private businesses introducing multiple behavioural change initiatives (i.e., economic (dis)incentives, product variation, and legislation) to reduce Australia's single-use plastic consumption, sociocultural factors remain an under-examined and addressed key element in its national environmental problem perpetuation. Theoretically, although it is well documented that 'social capital' theory can explain capacity for environmentally sustainable behaviour, knowledge gaps continue in research literature that identify why citizens choose to enact specific pro-environmental policy incentives that are preference-based, rather than punitive [20]. In democratic societies reliant upon a participatory system with legislative regulation, "regulatory instruments are more likely to be effective in situations where the majority of the target audience is willing, ready, and able to comply" [20]. However, identifying 'why' some individuals come to 'value' pro-environmental behaviour remains a social, and subsequently environmental, problem. A substantial body of research shows central tenets of social capital, specifically the public's level of environmental literacy, is insufficient for promoting pro-environmental behaviour where behavioural decisions are informed by a host of cultural reasons [21]-[26]. Further, as Ünal et al.'s (2018) research highlights and reviews, although general environmental literacy corresponds with increased environmental concern [27], individuals possessing high knowledge about environmental issues that their own behaviour negatively contributes to does not change behaviour if they do not personally value changing their behaviour to act pro-environmentally [22], [28]-[30].

The present study contributes findings from Australian social survey research to inform international literature investigating individual plastic packaging and purchasing behaviours alongside personal concern about 'waste reduction' and 'recycling' as pressing environmental issues. This furthers research questioning if 'personal values' affect/matter to pro-environmental behaviour, as well as if what has come to be known as the 'green attitude-behaviour gap' [31], where pro-environmental attitudes fail to manifest in pro-environmental behaviour, manifests in the research sample. We propose these may be two key areas requiring concerted policy action to change consumption practices, given the gap between pro-environmental views and behaviour allegedly relates to the majority of the population [31]. Technological advances require legislative/policy enforcement supported by widespread cultural change to manage the distribution of existing plastics and create alternative products/practices that discourage, or prevent, exponential growth in plastic consumption and environmental contamination as human population growth and urbanisation progress. The recent ratification of Australia's 2025 National Packaging Targets, which seek to end the consumption of any plastic packaging that cannot be reusable, recycled, or compostable by 2025 , will provide key stakeholders, such as local and state governments, packaging industries, and waste repurposing innovators, the impetus to work together to address technical issues for an environmental benefit [4]. By offering insights from an organisational study, this paper aims to inspire the conduct of national and international research that identifies how a culture of environmental sustainability and responsibility may come to represent national values and reflect widespread individual and collective action.

\section{METHODS}

Mixed-methods, exploratory, descriptive statistics (crosstabs, correlations, frequencies), and content analysis of qualitative data are used to analyse 412 online social surveys voluntarily completed by members of an Australian organisation to identify what individuals thought were the primary environmental problems affecting their lives and explore pro-environmental actions personally undertaken. Human research ethics approval was obtained and surveys were conducted using a secure, password-protected system to protect the data's integrity. Questions asked what environmental actions individuals took, or chose not to do, for a range of environmental sustainability topics and tested general environmental literacy using open and close-ended questions informed by existing research literature. The survey's face validity was achieved by completing a pilot project to identify and refine questions where pilot responses illustrated ambiguity in understanding any questions' intent [32]. Cross-coder reliability checking was employed for the qualitative content analysis to support accurate reflection of respondents' responses in data categorisation [33]. The anonymous, online nature of the data collection tool minimised social desirability reporting biases for individual actions, an issue noted for interview-based collection methods [31], which contributes to the 'authenticity' [32] of the data collected. Nevertheless, as exploratory, mixed-methods research, findings are not representative of broader populations and are best interpreted as a reflection of respondents' behaviours and perceptions.

This paper answers two research questions:

RQ1: Are there significant demographic associations identifying who is most likely to: a. avoid consuming plastic bottled water, b. take their own shopping bags, c. take their own reusable coffee cups to stores, or d. consider the environmental impact of packaging when making purchase decisions?

RQ2: Are individuals who articulate 'recycling,' 'packaging/plastic consumption', and/or 'waste reduction/management' as environmental problems affecting their lives more likely to a. avoid bottled water, b. take their own shopping bags to stores for groceries and/or clothing, c. 
use reusable coffee cups, or, d. consider the environmental impact of packaging when making purchase decisions?

By answering these questions, the research seeks to inform organisational practice, policy, and academic research interested in better understanding the prominence of consumer waste as a pressing personal environmental problem and if such awareness/valuation correlates with behaviours that reduce plastic waste/packaging by recycling and/or avoidance.

Qualitative content of the 'pressing environmental problems' individuals stated personally affect their lives is quantitatively analysed with personal consumption behaviours for 3 'disposable plastic products' (bottled water, coffee cups, plastic bags). The independent variables (demographics) for RQ1 are 'Age', 'Gender', 'Education', and 'Rurality'. The dependent variables are 'BuyPlasticBottledWater', 'TakeOwnGroceryBags', 'TakeOwnShoppingBags', 'UseKeepCups', and 'ConsiderPackaging'. Dependent variables had four answer choices ('always', 'once', 'mostly', or 'never'). 'Age' and 'education' collected ratio-level data recoded into ordinal categories. 'Gender' and 'rurality' were dichotomised into 'male/female' and 'yes/no', with rurality defined by place of current residence. To answer RQ2, respondents' qualitative identification of environmental problems they felt affected their life were analysed by content to find those related to plastic, recycling, waste/landfill, and packaging. The nominal variable 'Waste' ( $1=$ yes, $2=$ no) was created to locate individuals concerned about the environmental impact of garbage. Finally, 'Waste' was tested against the four pro-environmental behaviour variables to identify trends and associations.

\section{RESUlTS AND DisCUSSION}

For RQ1, a weak positive association emerged between rural location and buying bottled water $(0.115, p=0.05$, $n=406$ ). Rurality was insignificant for all other dependent variables. Gender significantly correlated with shopping bags women were more likely to take their own shopping bag for non-food items than men $(0.238, p=0.00, n=403)$ and to bring their own cup to cafes $(0.133, p=0.00, n=399)$. Greener actions by women has been noted in other studies, although the link to environmental attitudes or concerns is less consistent [34]. Higher education only achieved a weak positive association with taking one's own grocery bags (0.107, $p=0.05, n=407)$. Although this finding lends support from an Australian sample to other research exploring a range of cultures/places, including India, contrastingly, education was not the only, or most, significant demographic relationship with environmentally-conscious consumer behaviour [35].

Age yielded stronger associations with three of the four pro-environmental behaviours; older individuals were more likely to bring shopping bags to the supermarket $(0.269$, $p=0.00, n=403)$ and other stores $(0.157, p=0.00, n=403)$, and buy less bottled water $(-0.169, p=0.00, n=404)$. These results are consistent with age-related findings elsewhere [36], [37], notably that even when younger cohorts express greater interest in, or awareness of, environmental issues, in consumer settings, older respondents are more likely to demonstrate pro-environmental behaviours [34]. No demographic variables were associated with considering the environmental impacts of product packaging when making purchasing decisions.

Results for RQ2 found a third $(33 \% / \mathrm{n}=138)$ of the sample articulated consumer waste-related concerns as key environmental problems personally affecting their lives (see Fig. 1).

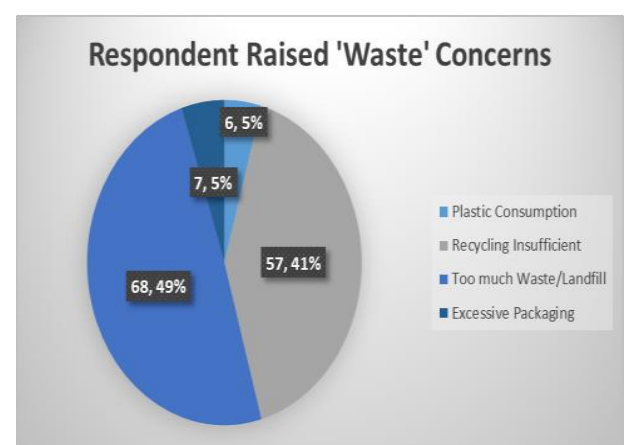

Fig. 1. Respondent raised waste concerns noted as affecting their lives.

Four content categories reflected all waste concerns the 138 respondents expressed: insufficient recycling, too little waste reduction measures, concern about plastics, and insufficient measure to stop the 'excessive' plastic product 'packaging'. Demographically, education (0.098, $p=0.05$, $n=405)$ and gender $(-0.120, p=0.05, n=407)$ were weakly associated with all 'Waste Concerns', with higher educated females more likely to be concerned than lower educated males. Clark et al. (2019), in their review of the demographic influences of pro-environmental behaviour, note women consistently demonstrate a greater awareness of the potentially negative environmental impacts of their actions and decisions. The present study likewise found personal concern, or 'valuing', how waste affects the environment is exhibited more by women than men. Waste concern, however, proved insignificant to adopting any of the five waste-reducing behaviours tested (Table I).

The majority (57\%) of those self-articulating 'too much waste' or 'insufficient recycling' are environmental problems affecting their lives never took a reusable coffee cup when they went to a café for take-away and just 4\% 'always' did. In contrast, respondents identifying a wide range of 'other' environmental problems - none related to 'garbage' reported higher waste-reduction behaviours, with more (9\%) 'always' taking a reusable cup and nearly the same percentage doing this once, sometimes, or never. It is possible respondents made inadequate connections between their behaviours and the very issues they expressed concern about, as others also found a gap, possibly intentional, between environmentally-conscious consumer behaviour and implications for the environment [3].

Conceptually, given the research environment had widespread advertising promoting reusable cups and was pre-COVID-19, and the behaviour entailed little economic cost, neither risk, nor social capital theories appear useful for understanding why $62 \%$ self-identifying concern about consumer waste's negative environmental impact (who did not select 'not applicable' to consuming take-away) engaged 
in this 'simple' pro-environmental behaviour never, or 'once'. At least three possibilities exist: it's a 'low interest' environmental concern, ambiguity/confusion exists about plastic-derived cups' 'recycle-ability', and/or human behaviour differs from intentions/ideological concerns. Further, respondents reporting environmental problems unrelated to 'waste' did not predispose them to different coffee cup behaviour. Coffee cup waste is an applied and academic issue receiving much global attention from production to consumption. Current findings suggest pursuing 'effective' negative incentives (i.e. fee for disposable cup consumption rather than discount for bringing a reusable cup) are worthwhile [38] because, regardless of personal environmental concerns, the majority bought and threw away disposable cups. In a COVID-19 historical moment, research/action emphasis may benefit from shifting environmental responsibility away from consumers to producers and governments, by creating only environmentally-neutral packaging options.

TABLE I: RESPONDENT CONCERN ABOUT WASTE REDUCTION FOR ENVIRONMENTAL REASONS WAS INSIGNIFICANT TO WASTE-MINIMISING

\begin{tabular}{|c|c|c|c|c|c|}
\hline \multicolumn{6}{|c|}{ BEHAVIOURS } \\
\hline $\begin{array}{l}\text { Concerned } \\
\text { about } \\
\text { Recycling, } \\
\text { Plastics \& } \\
\text { Waste } \\
\text { Reduction }\end{array}$ & $\begin{array}{l}\text { I take my } \\
\text { own } \\
\text { coffee cup } \\
\text { to cafés } \\
\text { for } \\
\text { take-away }\end{array}$ & $\begin{array}{l}\text { I take my } \\
\text { own bags } \\
\text { for } \\
\text { grocery } \\
\text { shopping }\end{array}$ & $\begin{array}{l}\text { I take my } \\
\text { own bags } \\
\text { for } \\
\text { general } \\
\text { shopping }\end{array}$ & $\begin{array}{l}\text { I base } \\
\text { product } \\
\text { choice } \\
\text { on the } \\
\text { amount } \\
\text { of } \\
\text { packing }\end{array}$ & $\begin{array}{l}\text { I buy } \\
\text { bottled } \\
\text { water }\end{array}$ \\
\hline Yes & $\begin{array}{l}\text { Always } 6 \\
(4 \%) \\
\text { Mostly } 44 \\
(32 \%) \\
\text { Once } 9 \\
(6 \%) \\
\text { Never } 77 \\
(57 \%)\end{array}$ & $\begin{array}{l}\text { Always } \\
32(23 \%) \\
\text { Mostly } \\
91(66 \%) \\
\text { Once } 8 \\
(6 \%) \\
\text { Never } 6 \\
(4 \%)\end{array}$ & $\begin{array}{l}\text { Always } \\
12(9 \%) \\
\text { Mostly } \\
71(52 \%) \\
\text { Once } 11 \\
(8 \%) \\
\text { Never } 42 \\
(31 \%)\end{array}$ & $\begin{array}{l}\text { Always } \\
6(4 \%) \\
\text { Mostly } \\
80 \\
(58 \%) \\
\text { Once } 10 \\
(7 \%) \\
\text { Never } \\
42 \\
(31 \%)\end{array}$ & $\begin{array}{l}\text { Always } \\
5(4 \%) \\
\text { Mostly } \\
51 \\
(37 \%) \\
\text { Once } 27 \\
(19 \%) \\
\text { Never } \\
55 \\
(40 \%)\end{array}$ \\
\hline No & $\begin{array}{l}\text { Always } 24 \\
(9 \%) \\
\text { Mostly } 80 \\
(30 \%) \\
\text { Once } 13 \\
(5 \%) \\
\text { Never } 151 \\
(56 \%)\end{array}$ & $\begin{array}{l}\text { Always } \\
66(24 \%) \\
\text { Mostly } \\
170 \\
(63 \%) \\
\text { Once } 9 \\
(3 \%) \\
\text { Never } 26 \\
(10 \%)\end{array}$ & $\begin{array}{l}\text { Always } \\
38(14 \%) \\
\text { Mostly } \\
120 \\
(44 \%) \\
\text { Once } 22 \\
(8 \%) \\
\text { Never } 92 \\
(34 \%)\end{array}$ & $\begin{array}{l}\text { Always } \\
14(5 \%) \\
\text { Mostly } \\
150 \\
(56 \%) \\
\text { Once } 25 \\
(9 \%) \\
\text { Never } \\
83 \\
(30 \%)\end{array}$ & $\begin{array}{l}\text { Always } \\
9(3 \%) \\
\text { Mostly } \\
93 \\
(34 \%) \\
\text { Once } 47 \\
(17 \%) \\
\text { Never } \\
122 \\
(45 \%)\end{array}$ \\
\hline
\end{tabular}

The majority $(56 \%)$ of the whole sample bought bottled water regardless if they identified 'waste' an environmental problem affecting their life. Further, buying plastic water bottles was a 'regular' behaviour by $41 \%$ of those concerned about the environmental impact of plastic, packaging, and/or waste pollution, than those unconcerned (37\%). These findings may suggest belief in technological solutions, such as the advertised reduced plastic content of newer containers and/or inclusion of plant-based plastics [6], may reflect low environmental literacy or poor understanding about the 'permanence' of plastics, and/or scientific awareness of recycling's inability to solve environmental problems arising from humanity's plastic dependency. Irrespective of implications, findings further Australian research showing most research participants buy bottled water, regardless of their environmental literacy, concerns, or awareness [14].
Legislation requiring Australian supermarkets to stop providing free shopping bags likely influenced this consumer behaviour. Similarly, the social behaviour's visual cues of a trolley full of 'environmentally-friendly' bags likely contributes to reusable bags social normativity, an influence considered stronger than legislation [31], [34]. Results show variation between taking one's 'own' bag for groceries versus other purchases. For example, 10\%-13\% 'never', or 'just once', brought their own grocery bags compared with $39 \%-42 \%$ doing the same for 'non-grocery' shopping. Whether due to culturally-affirming or economic reasons, greater pro-environmental behaviour emerged for the same action - taking your own shopping bag - in one social setting than another. Propensity to take one's own bag, but not one's own cup, is a finding consistent with research noting negative consequences (specifically a small cost in UK trials) act as a greater incentive for action than price reduction [3]. Further, the inconvenience of carrying a reusable cup, particularly post-use, is greater than carrying a foldable reusable bag, and thus acts as an added barrier to greater reusable cup adoption, whilst coffee cup recycling schemes requiring drop-off at specific locations are perceived too inconvenient or unsuitable to meaningfully address waste issues [39].

Despite noted global plastic bag bans, variable consumer embracing [40], analyses of environmental impact [11], [41], and current findings suggest greater environmental benefit may be gained by legislatively minimising waste stream production that does not rely on consumers' perception of convenience, or willingness, to act. While consumers may be important stakeholders, they add an inconsistent and complex dimension that can leave individual industries and businesses stretched to effectively meet environmental needs while also placating their customers [39].

\section{CONCLUSIONS}

Analysis of 412 online social surveys completed by members of an Australian organisation revealed most (67\%) did not identify 'landfill' or 'waste management' as major environmental concerns affecting their lives. This, however, did not prevent them from partaking in waste-reduction activities. For example, the majority (62\%) of those unconcerned about plastics or waste pollution still avoided buying bottled water, or did so just 'once' during the six months prior to being asked. Likewise, 61\% 'mostly' or 'always' made purchase-decisions based on how much packaging it contained. Given that respondents highly concerned about waste management similarly considered packaging (62\%) and 'hardly ever', or 'never', purchased bottled water $(59 \%)$, this suggests the 'centrality' of waste management among individuals' environmental concerns is a poor indicator of their waste-reduction behaviours, including the tendency to consume disposable coffee cups. Likewise, with most respondents $(61 \%-63 \%)$ regularly consuming disposable coffee cups, this remains a 'landfill' challenge whilst they remain non-recyclable and contain plastic.

Greater variation emerged among pro-environmental behaviours survey respondents undertook than between those articulating 'waste/landfill' (and its contents) were/were not an environmental problem affecting their personal lives. For 
example, observed differences emerged in 'shopping bag' behaviour; $87-89 \%$ of the whole sample regularly 'took their own bags' for groceries, compared with $58-61 \%$ doing this for 'non-food' items. This finding suggests factors external to individual environmental concern about landfill at play. Since legislation, cultural change, and discontinuation of 'free' bag provision at supermarkets all encourage behavioural change towards 'reusing' shopping bags for groceries, whilst non-food retailers may still provide 'free' bags, results suggest environmental benefit may be gained if all retailers stopped supplying bags without consumer cost.

Findings further research noting 'personal values' and environmental awareness fail to affect pro-environmental behaviour, described as the 'green attitude-behaviour gap' [31]. High disposable coffee cup consumption, however, coexisted with high consideration of product packaging, regardless if individual concern manifested about the environmental impact of 'waste'. With 'legislated' plastic plastic bags - the only consumer product showing substantial behavioural difference, environmental 'concern', as an expression of values, may be mitigated by product supply. Respondents 'behaved' pro-environmentally for some 'wasteful' products, and not others, irrespective of waste concern.

Thus, removing consumer 'preference' from human behaviours having highly negative environmental consequences appears, consistent with prior studies, the best way to promote ecological health. Finally, given the strongest associations with greater pro-environmental behaviour were found for older age and being female, further research is needed to identify if these demographic trends exist beyond the organisation examined in a nationally representative sample so non-legislated changes may be accompanied by demographically-targeted campaigns.

\section{CONFLICT OF INTEREST}

The authors declare no conflict of interest.

\section{AUTHOR CONTRIBUTIONS}

Dr. Crampton contributed to the project design, survey construction and literature searching. Dr. Ragusa lead the project design, survey conduct, data analysis and writing.

\section{REFERENCES}

[1] S. Hassan and I. U. Haq, "Pervasive pollution problems caused by plastics and its degredation," iJOE, vol. 15, p. 29, 2019.

[2] D. Vethaak and H. A. Leslie, "Plastic debris is a human health issue," Environ. Sci. Technol., vol. 50, p. 6825, 2016.

[3] D. Maye, J. Kirwan, and G. Brunori, "Ethics and responsibilisation in agri-food governance: The single-use plastics debate and strategies to introduce reusable coffee cups in UK retail chains," Agri. Human Values, vol. 36, p. 301, 2019.

[4] Australian Packaging Covenant Australian Packaging Covenant Strategic Plan 2017-2022, 2019.

[5] K. O'Farrell, 2017-18 Australian Plastics Recycling Survey - National Report, 2019.

[6] L. Magnier and J. Schoormans, "Consumer reactions to sustainable packaging: The interplay of visual appearance, verbal claim and environmental concern," J. Environ. Psychol., vol. 44, p. 53, 2015.

[7] F. Ribeiro, J. W. O'Brien, T. Galloway, and K. V. Thomas, "Accumulation and fate of nano- and micro-plastics and associated contaminants in organisms," Trends Analyt. Chem., vol. 111, p. 139, 2019.
[8] Y. Yu and J. Wang, "Types of E-waste and hazard analysis to animals and plants," Revista Cientifica, vol. 29, p. 742, 2019.

[9] K. Willis, C. Maureaud, C. Wilcox, and B. D. Hardesty, "How successful are waste abatement campaigns and government policies at reducing plastic waste into the marine environment?" Mar. Policy, vol 96 , p. $243,2018$.

[10] J. K. Abbott and U. R. Sumaila, "Reducing marine plastic pollution: Policy insights from economics," Rev Environ Econ Policy, vol. 13, p $327,2019$.

[11] A. Macintosh, A. Simpson, T. Neeman, and K. Dickson, "Plastic bag bans: Lessons from the Australian Capital Territory," Resour. Conserv. Recycl., vol. 154, p. 104638, 2020.

[12] S. Zweden, "Tip of the landfill: The ABC's war on waste," Metro Magazine, vol. 197, no. 48, 2018.

[13] Clean Up Australia, The 2019 Rubbish Report: National, 2019.

[14] A. Crampton and A. T. Ragusa, "Exploring perceptions and behavior about drinking water in Australia \& New Zealand: Is it risky to drink water, when \& why?" Hydrology, vol. 3, p. 8, 2016

[15] G. S. Levy and W. S. Shrapnel, "Quenching Australia's thirst: A trend analysis of water-based beverage sales from 1997 to 201," Nutr. Diet, vol. 71, p. 193, 2014

[16] M. F. Dobbie and R. R. Brown, "A framework for understanding risk perception explored from the perspective of the water practitioner," Risk Anal., vol. 34, p. 294, 2014.

[17] S. S. Andra, K. C. Makris, J. P. Shine, and C. Lu, "Co-leaching of brominated compounds and antimony from bottled water," Environ. Int., vol. 38, p. 45, 2012.

[18] N. Belzile, Y. W. Chen, and M. Filella, "Human exposure to antimony: I. Sources and intake," Crit. Rev. Environ. Sci. Technol., vol. 14, p. 1309, 2011.

[19] A. Guart, F. Bono-Blay, A. Borrell, and S. Lacorte, "Migration of plasticizersphthalates, bisphenol a and alkylphenols from plastic containers and evaluation of risk," Food Addit. Contam., vol. 28, p. 676, 2011.

[20] M. H. Jin and A. J. Shriar, "Exploring the relationship between social capital and individuals' policy preferences for environmental protection: A multinomial logistic regression analysis," J. Environ. Policy. Plann, vol. 15, p. 427, 2013.

[21] A.T. Ragusa, "Awareness that coal-powered energy is environmentally degrading insignificantly affects its consumption," E3S Web Conf., vol. 158 , p. 02001, 2020.

[22] A. B. Unal, L. Steg, and M. Gorsira, "Values versus environmental knowledge as triggers of a process of activation of personal norms for eco-driving," Environ. Behav., vol. 50, no. 1092, 2018.

[23] L. Schmidt, A. Horta, A. Correia, and S. Fonseca, "Generational gaps and paradoxes regarding electricity consumption and saving," Nat. Cult., vol. 9, no. 183, 2014.

[24] B. Fischhoff and D. A. Scheufele, "The science of science communication II," Proc. Natl. Acad. Sci., vol. 111, p. 13583, 2014.

[25] S. Misra and D. Stokols, "Psychological and health outcomes of perceived information overload," Environ. Behav., vol. 44, p. 737, 2012.

[26] L. Brown, D. Robertson, "An analysis of energy conservation among U.S. age cohorts," Acad. Bank. Stud. J., vol. 10, no. 45, 2011.

[27] J. Shi, V. H. M. Visschers, and M. Siegrist, "Public perception of climate change: The importance of knowledge and cultural worldviews," Risk Anal., vol. 35, p. 2183, 2015.

[28] J. W. Bolderdijk, M. Gorsira, K. E. Keizer, and L. Steg, "Values determine the (in)effectiveness of informational interventions in promoting pro-environmental behaviour," PLOS ONE, vol. 8, p. 83911, 2013.

[29] C. Tobler, V. H. M. Visschers, and M. Siegrist, "Consumers' knowledge about climate change," Clim. Chan., vol. 114, no. 189, 2012.

[30] I. Ajzen, N. M. Joyce, S. Sheikh, and N. G. Cote, "Knowledge and the prediction of behavior: The role of information accuracy in the theory of planned behavior," Basic. Appl. Soc. Psych., vol. 33, no. 101, 2011.

[31] M. L. Johnstone and S. Hooper, "Social influence and green consumption behaviour: A need for greater government involvement," J. Marketing Manag., vol. 32, no. 827, 2016.

[32] W. L. Neuman, Social Research Methods, 7th Edition, 2014.

[33] S. Polgar and S. Thomas, Introduction to Research in the Health Sciences, 7th Edition, 2020.

[34] R. A. Clark, D. L. Haytko, C. M. Hermans, and C. S. Simmers, "Social influence on green consumerism: Country and gender comparisons between China and the United States," J. Int. Consum. Mark, vol. 31, p. $177,2019$. 
[35] A. Gupta and U. Singh, "Factors influencing environmentally responsive consumption behavior in India," SCMS J. Indian Manag., vol. 15 , no. $87,2018$.

[36] L. Panzone, D. Hilton, L. Sale, and D. Cohen, "Socio-demographics, implicit attitudes, explicit attitudes, and sustainable consumption in supermarket shopping," J. Econ. Psychol., vol. 55, no. 77, 2016.

[37] J. Patel and A. Modi, "Pro-environmental behavior and socio-demographic factors in an emerging market," Asian J. Bus. Ethics, vol. 6, p. 189, 2017.

[38] W. Poortinga, N. Nash, and L. Hoeijmakers, "Rapid review of charging for disposable coffee cups and other waste minimisation measure," 2019.

[39] J. Ferreira, "Fostering sustainable behaviour in retail: Looking beyond the coffee cup," Soc. Business, vol. 8, no. 21, 2018.

[40] D. Xanthos and T. R. Walker, "International policies to reduce plastic marine pollution from single-use plastics (plastic bags and microbeads): A review," Mar. Pollut. Bull., vol. 118, no. 17, 2017.

[41] T. Herberz, C. Barlow, and M. Finkbeiner, "Sustainability assessment of a single-use plastics ban," Sustain, vol. 12, no. 3746, 2020.

Copyright $\odot 2021$ by the authors. This is an open access article distributed under the Creative Commons Attribution License which permits unrestricted use, distribution, and reproduction in any medium, provided the original work is properly cited (CC BY 4.0).

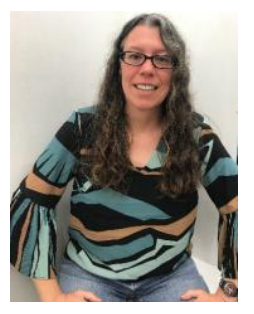

Angela T. Ragusa is editor-in-chief of the journal Rural Society and a sociologist with $>25$ years of research and teaching experience in communication and media studies, environmentalism, social psychology, inequality, culture, and health/science. Angela has more than 85 academic publications, including 3 books, and has supervised/graduated several research students, the most recent being a science communication project about the anti-vaccination movement/attitudes investigating social media using discourse analysis.

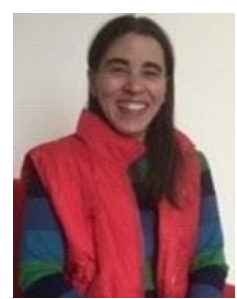

Andrea L. Crampton is a senior lecturer in microbiology and author of over 40 papers in the fields of parasitology, microbiology, water quality and public understanding of health, science and environmental information. 